\title{
Harvesting energy from the dynamic deformation of an aircraft wing under gust loading
}

\author{
Michele Pozzi $^{\mathrm{a}^{*}}$, Shijun Guo ${ }^{\mathrm{b}}$, Meiling Zhu ${ }^{\mathrm{a}}$ \\ ${ }^{a}$ School of Applied Sciences \\ Cranfield University, Bedfordshire, MK43 0AL, UK \\ *e-mail:m.pozzi@cranfield.ac.uk (corresponding author) \\ ${ }^{\mathrm{b}}$ School of Engineering, \\ Cranfield University, Bedfordshire, MK43 0AL, UK
}

\begin{abstract}
Weight reduction and maintenance simplification are high in the agenda of companies and researchers active in the aerospace sector. Energy harvesters are being investigated because they enable the installation of wireless sensor nodes, providing structural health monitoring of the aircraft without additional cabling. This paper presents both a weightoptimized composite wing structure and a piezoelectric harvester for the conversion of mechanical strain energy into electrical energy. Finite elements modelling was used for the minimum-weight optimisation within a multi-constraints composite wing framework (strength, damage tolerance, flutter speed and gust response). The resulting structure is $29 \%$ more compliant than the original one, but is also $45 \%$ lighter. A strain map was elaborated, which details the distribution of strain on the wing skin in response to gust loading, indicating the optimal locations for the harvesters. To assess the potential for energy generation, a piezoelectric harvester fixed to a portion of the wing was modelled with a multiphysics finite elements model developed in ANSYS. The time-domain waveforms of the strain expected when the aircraft encounters a gust (gust frequencies of 1,2, 5 and $10 \mathrm{~Hz}$ were considered) are fed into the model. The effects of harvester thickness and size, as well as adhesive thickness, were investigated. Energy generation exceeding $10 \mathrm{~J} / \mathrm{m}^{2} \mathrm{in}$ the first few seconds from the beginning of the gust is predicted for $100 \mu \mathrm{m}$-thick harvesters. The high energy density, low profile and weight of the piezoelectric film are greatly advantageous for the envisaged application.
\end{abstract}

Keywords: piezoelectric energy harvesting, structural health monitoring, composite wing, gust response, PZT generator, predictive maintenance.

\section{INTRODUCTION}

A prime focus in the design of modern civil airframes is on weight reduction, as this has a major impact on fuel consumption, and thence on the economy and environmental impact of air transport. Naturally, flight safety is of paramount importance, and this requires careful maintenance, which represents another major cost incurred in the operation of an airline fleet. A great part of current aeroplane maintenance is unscheduled, meaning that it was carried 
out in response to an imminent fault ${ }^{1}$. This is costly, as the aeroplane may have to be taken out of service at an unscheduled time, which cannot efficiently be compensated for. Current trends are towards on condition maintenance, where the condition of a component is assessed to permit intervention before it will develop a fault, as many modes of failure do show early warning signs. Visual or instrumental inspections are carried out by human operators for the early identification of damages, so that preventive maintenance can be carried out if needed. A further step is the shift towards predictive maintenance, facilitated by on-line monitoring of the structure. It comes therefore as no surprise that there is great interest in Structural Health Monitoring (SHM) systems for aircraft, whose role is to monitor and report on the conditions of vital airframe components. A significant obstacle to the widespread adoption of SHM systems is represented by the additional weight and complexity introduced by the wires that would supply them with power and transport the data collected. The natural solution to this problem is the adoption of wireless sensor nodes (WSNs), i.e. intelligent sensors capable of collecting the data and transmitting them wirelessly to a central hub on the aircraft. Some WSNs also carry the promise of being retrofittable to existing aircraft.

WSNs require a local source of power, which is best provided by maintenance-free solutions as afforded by energy harvesting $(\mathrm{EH})$ technologies, rather than replaceable or rechargeable batteries. A compelling approach to the provision of energy to WSNs on aircraft has been offered in a recent paper $^{2}$; the harvester uses the temperature differential between ground and cruising altitudes to drive a thermoelectric generator (TEG) via the flow of heat to and from a water reservoir. While its power generation, at $189 \mu \mathrm{W}$ during a 4-hour flight, is remarkable, the device is rather bulky and has a mass of about $30 \mathrm{~g}$, not including TEG and power management.

Piezoelectric materials can convert strain energy into electrical energy. The main advantage of harvesters based on the piezoelectric effect resides in their compactness and lightweight; for example, Churchill et al. ${ }^{3}$ have made a $17 \mathrm{~cm}^{2}$ harvester of piezoelectric fibres and tested it under harmonic excitation of frequencies between 60 and $180 \mathrm{~Hz}$, generating up to almost $0.8 \mathrm{~mW}$ with a strain of $3 \cdot 10^{-4}$ (i.e. $300 \mu$ strain). Within the context of structural monitoring, significant work has been done to scavenge environmental vibrations ${ }^{4}$, for example, Zhu et al. ${ }^{5}$ have developed a harvester based on a resonating cantilever to power a wireless sensor node.

This paper focuses on the direct conversion of strain energy resulting from wing vibrations into electricity by means of piezoelectric transducers. During normal flights, aircraft encounter gusts (air turbulence), which excite the vibrations of the wings, seen as cantilevered beams rooted on the fuselage. This results in alternating compressive/tensile strain on the upper and lower wing skin. The objective of the work is to estimate the energy that can be harvested by a PZT transducer during a gust event. The first part of the work presented here is the definition of a sample airframe for a large aircraft; the airframe has carbon/epoxy composite wing, which is optimized for minimum weight subject to multiple design constraints, such as a laminate failure criteria and wing flutter speed. The optimised airframe is then modelled to predict the dynamic response to a selection of gust loadings, with particular focus on the resulting strain levels in the wing skin during and after a gust load. Pozzi and $\mathrm{Zhu}^{6}$ have developed and validated a finite elements (FE) model that uses a transient analysis for the prediction of the energy harvesting performance of a piezoelectric material subject to arbitrary time-domain excitation. This model is adapted and used in the second part of the work, where the strain waveforms calculated before are used to predict the energy generation capability of a piezoelectric PZT transducer attached to the skin of the wing. A parametric study is carried out to investigate the effects of adhesive thickness and harvester size and thickness. 


\section{OPTIMIZED WING}

In this section the modelling framework for the wing structure is presented. The first subsection centres on the structure modelled and the loads applied. The second subsection presents the major results.

\subsection{AIRFRAME MODELLING}

A FE model of the composite wing box structure was created with the MSC.PATRAN/NASTRAN package. In the FE model, the wing skin, ribs and spar webs were modelled by using shell elements; the stringers and spar capes are modelled using beam element. In the dynamic and aeroelastic analysis, the engine was modelled as a concentrated mass located at the centre of gravity of the engine (Figure 1). The mass of the slat was distributed along the grids of the front spar; the aileron and flaps were modelled as concentrated mass connected to the rear spar. More data about the modelled aircraft are listed in Table 1.

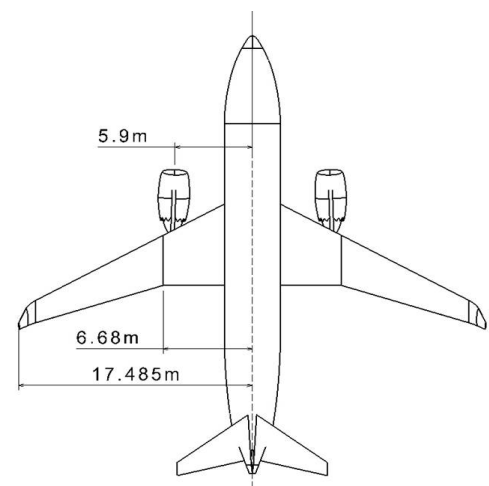

Figure 1. The wing dimensions and engine position of the example aircraft

A minimum-weight structural optimization was performed by tailoring the wing skin thickness and the laminate layup. The optimization was subject to multiple design constraints including strength, damage tolerance, flutter and gust response. Considering the damage tolerance, the maximum value of the laminate strain of the structural components was limited to 0.004 (4000 $\mu$ strain). For aeroelastic stability concern, the flutter velocity was set to be greater than $1.15 \cdot V_{\mathrm{D}}$, where $V_{0}$ is the equivalent flight speed $\left(V_{0}=230 \mathrm{~m} / \mathrm{s}\right)$.

Table 1. Some technical data of the aircraft design

\begin{tabular}{lrl}
\hline \multicolumn{1}{c}{ Description } & \multicolumn{2}{c}{ Values } \\
\hline Wing span & 33.48 & $\mathrm{~m}$ \\
\hline Fuselage length & 34.11 & $\mathrm{~m}$ \\
\hline Maximum take-off mass & 64580 & $\mathrm{~kg}$ \\
\hline Design payload & 12160 & $\mathrm{~kg}$ \\
\hline Design cruise speed & 0.78 & Mach \\
\hline Design cruise altitude & 11880 & $\mathrm{~m}$ \\
\hline Design mission range & 3700 & $\mathrm{~km}$ \\
\hline
\end{tabular}

In aircraft design, the gust may be represented with either discrete or continuous turbulence models. In the current 
investigation, the 1-cosine discrete gust model specified in the airworthiness regulation (CS-25) is used for its simplicity. The gust velocity profile of a 1-cosine model is expressed as:

$$
U=\frac{U_{d e}}{2}\left[1-\cos \left(\frac{\pi s}{H}\right)\right]
$$

Here, $U_{\mathrm{de}}$ is a specified design gust velocity; $s$ is the distance travelled by the aircraft since entering the gust region; $H$ is the gust gradient distance (the distance along the aircraft flight path for the gust to reach its peak velocity). According to CS-25, the maximum value for $U_{\mathrm{de}}$ is $17.6 \mathrm{~m} / \mathrm{s}$, whilst $H$ varies in the range from 9 to $107 \mathrm{~m}$. By assuming that the aeroplane flies at constant cruise speed, we can substitute $S(t)=V t$ in the equation, and $U$ becomes a function of time. It is then possible to extract an equivalent gust frequency from the equation. Taking an average value of $H=58 \mathrm{~m}$ and a flight speed $V=230 \mathrm{~m} / \mathrm{s}$, for example, a gust frequency of $2 \mathrm{~Hz}$ can be obtained from $\cos (4 \pi t)$. Considering the random feature of the air turbulence in real life, an aircraft could encounter a gust at any frequency within the range defined by $H$ and its velocity. Therefore, a range of gust frequencies is considered in the gust response analysis.

\subsection{THE OPTIMIZED WING AND THE GUST RESPONSE}

The weight optimization procedure was applied to a previously identified structure. The initial design offered a Failure Index (FI) of 0.57 , flutter speed of $714 \mathrm{~m} / \mathrm{s}$ at $26.5 \mathrm{~Hz}$ and maximum deflection under extreme gust loading of $418 \mathrm{~mm}$ at the wing tip, corresponding to a maximum strain of $3520 \mu$ strain in some areas of the wing skin. The initial wing box structure had a mass of $1022 \mathrm{~kg}$. After weight optimisation, a 45\% weight saving of the wing box structure was achieved as a result of the skin thickness reduction. As part of the results, the maximum FI increased to 0.62. The weight saving was limited by the constraint on the maximum permissible strain, which reached $4040 \mu$ strain at the root (Figure 2), still exceeding by only $1 \%$ the damage tolerance upper boundary. Although the flutter speed is reduced to $492 \mathrm{~m} / \mathrm{s}$, it still satisfies the design requirement of being above $1.15 \cdot \mathrm{V}_{\mathrm{D}}$ (CS-25 regulation). In addition, the gust response increased to a maximum deflection of $539 \mathrm{~mm}$ at the tip of the wing. The initial laminate layout for the wing skin was [(45/90/-45/0) $n$ $\left.(45 /-45)_{r}\right]$ whilst the optimised layout was $\left[(46 / 86 /-42 / 0)_{n}(47 /-44)_{r}\right]-$ in both cases $n$ and $r$ vary along the wing span $(n=3,4,5$ and $r=0,1)$.

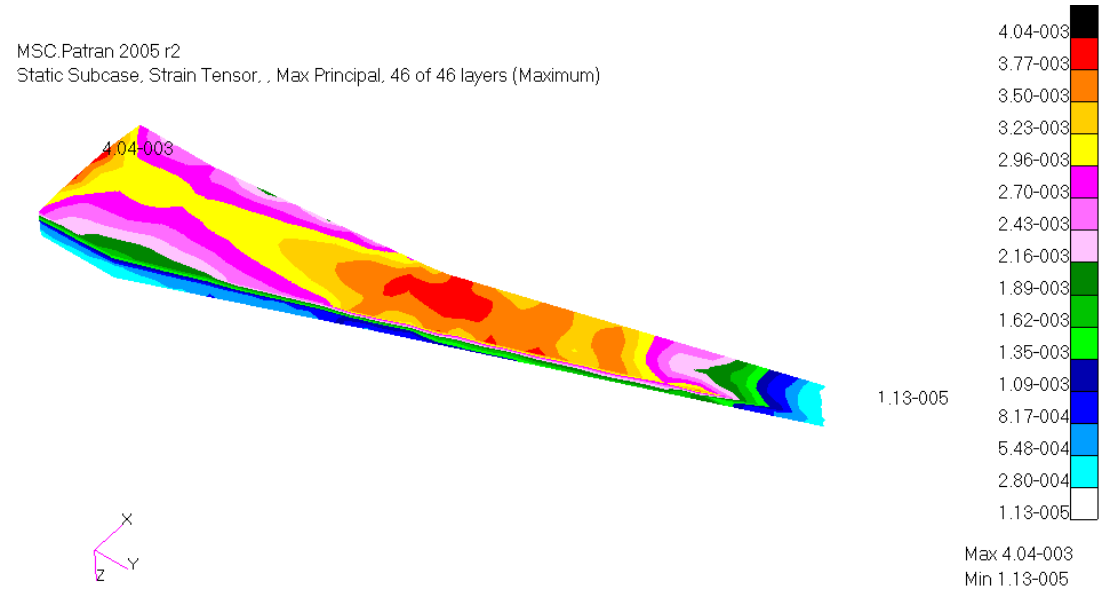

Figure 2. Strain distribution on the wing skin under maximum load. 


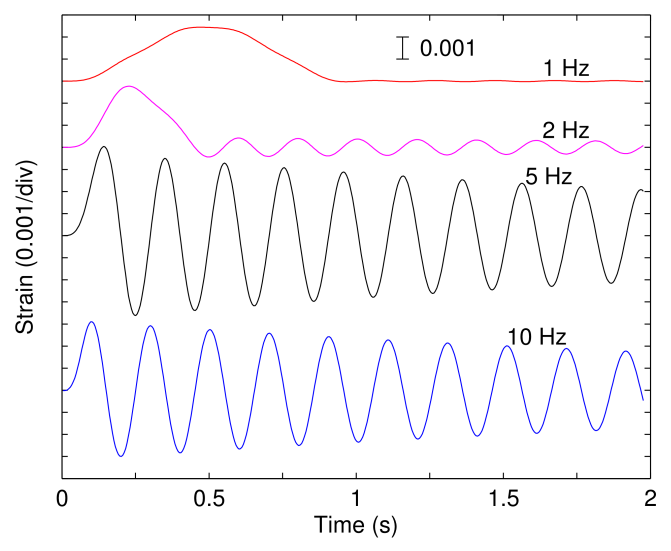

Figure 3. Time domain signal of the maximum strain

Of particular interest for the energy harvesting capabilities of the proposed harvester is the time response of the wing to gust loading. Figure 3 shows the time dependence of the maximum strain for the four gust frequencies investigated.

\section{MODELLING OF THE ENERGY HARVESTER}

This section focuses on the modelling of the proposed energy harvester: the first subsection describes the modelling framework, whilst the second presents the results of several parametric investigations that were carried out.

\subsection{ENERGY HARVESTING: MODELLING FRAMEWORK}

For the prediction of the energy harvesting capabilities of a piezoelectric film attached to the surface of the wing, a FE model was developed in ANSYS 13.0 (ANSYS Inc. Canonsburg, PA, USA). The solid model is a 3-mm thick substrate with a piezoelectric film attached at its centre. The substrate is a section wing made of HexPly 3501-6 epoxy matrix and AS4 fibres composite having the layout [(46/86/-42/0 $\left.)_{4}\right]$, as obtained from the previous wing optimisation. The properties of the cured laminate plies are given in Table 2. It was assumed that the PZT film was bonded to the composite substrate with a structural epoxy adhesive (DP460 from 3M, relevant properties in Table 3) of thickness selected within the range 5 to $50 \mu \mathrm{m}$. The piezoelectric material chosen is PZT-5H (properties in Table 4) for its good energy generation characteristics. A range of values of thickness was explored, from 10 to $200 \mu \mathrm{m}$, as well as a range of side lengths from $2 \times 2 \mathrm{~mm}^{2}$ to $10 \times 10 \mathrm{~mm}^{2}$. Naturally, a real-life harvester fixed to the wing could be much larger; the upper value explored in this work was dictated by the computational cost of simulation. Exploiting the symmetry of the configuration, only $1 / 4$ of the geometry was actually modelled with FE; parameters indicated in the following and the results reported are rescaled for the full device. The substrate was meshed with Layered Solid elements, the epoxy adhesive with Structural Solid elements and the PZT film with Piezoelectric Solid elements, which have electrical as well as mechanical capabilities, permitting the modelling of the piezoelectric effect in a multi-physics model. Electrodes were defined on the two sides of the piezoelectric film, by coupling the voltage DoF of the nodes, and connected to a Circuit element configured as a resistor whose value was made to vary to explore its effect on power output. The loading data was applied to the composite substrate as a displacement constraint at the edges, so as to produce within the substrate the time-dependent strain signal on the wing (Figure 3). In recognition of the fact that data in Figures 1 and 2 are for an extreme gust $(\mathrm{V}=17.6 \mathrm{~m} / \mathrm{s})$ and that the strain is not uniform across the wing surface, for the power prediction calculation the peak strain was assumed to be only $1300 \mu$ strain, i.e. the input strain waveforms to the coupled piezoelectric- 
mechanical FE model were approximately $1 / 3$ of those in Figure 2.

Table 2. Properties of the cured laminate plies used in the modelling 7 .

\begin{tabular}{lc}
\hline \multicolumn{2}{c}{ Mechanical properties (HexPly ${ }^{\circledR}$} \\
\hline 3501-6 AS4 ) \\
\hline Young's modulus (long.) & $142 \mathrm{GPa}$ \\
\hline Poisson's modulus (transv.) & $10.3 \mathrm{GPa}$ \\
\hline In-plane shear modulus & 0.27 \\
\hline
\end{tabular}

Table 3. Material properties of the epoxy adhesive (DP460 from 3M) ${ }^{8}$

\begin{tabular}{lc}
\hline \multicolumn{2}{c}{ Mechanical properties (DP460) } \\
\hline Young's modulus & $2.7 \mathrm{GPa}$ \\
\hline Poisson's ratio & 0.4 \\
\hline
\end{tabular}

Table 4. Material properties of the piezoelectric film in the FE model.

\begin{tabular}{lr}
\hline \multicolumn{2}{c}{ Material properties (PZT-5H) } \\
\hline $\mathrm{c}^{\mathrm{E}}{ }_{11}$ & $62 \mathrm{GPa}$ \\
\hline $\mathrm{c}^{\mathrm{E}}{ }_{33}$ & $50 \mathrm{GPa}$ \\
\hline $\mathrm{d}_{31}$ & $-32010^{-12} \mathrm{~m} / \mathrm{V}$ \\
\hline $\mathrm{d}_{33}$ & $65010^{-12} \mathrm{~m} / \mathrm{V}$ \\
\hline$\varepsilon^{\mathrm{T}}{ }_{11}$ & 3600 \\
\hline$\varepsilon^{\mathrm{T}}{ }_{33}$ & 3800 \\
\hline
\end{tabular}

\subsection{ENERGY HARVESTING: MODELLING RESULTS}

A set of parameters was identified as worthy of investigation. Starting from the reference condition of a $5 \times 5 \mathrm{~mm}^{2} \mathrm{square}$ film of PZT, of thickness $100 \mu \mathrm{m}$, bonded with a $5 \mu \mathrm{m}$-thick layer of DP460 adhesive to the composite, which is subjected to the $5 \mathrm{~Hz}$ gust loading, the following parameters were changed one at a time to assess their effect on energy generation: thickness of PZT (from 10 to $200 \mu \mathrm{m}$ ); size of PZT (from $2 \times 2 \mathrm{~mm}^{2}$ to $10 \times 10 \mathrm{~mm}^{2}$ ); thickness of adhesive (from 5 to $50 \mu \mathrm{m}$ ); gust frequency (from 1 to $10 \mathrm{~Hz}$ ). For each new set of parameters, several solutions were performed to identify the optimal electrical load; a set of data obtained in this way (total energy versus electrical load) is shown in Figure 4 as an example. 


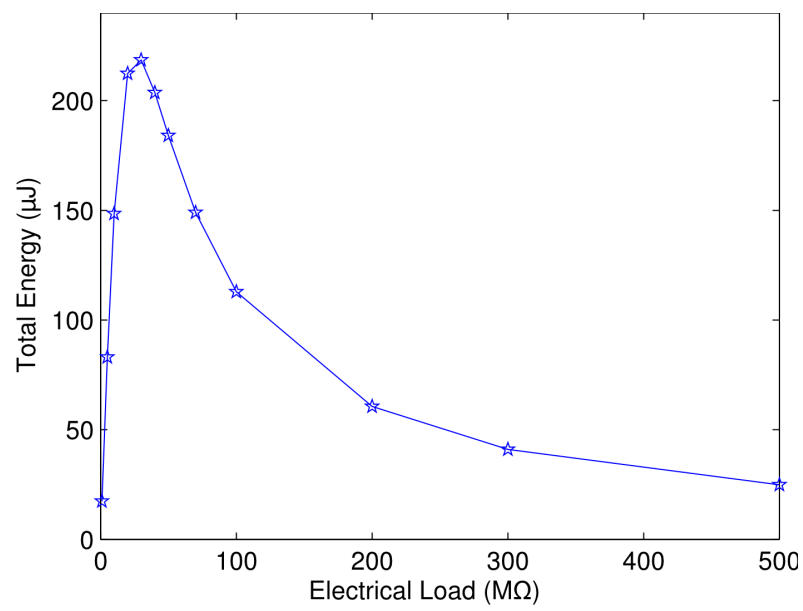

Figure 4. Total energy collected from the $\mathrm{EH}$ as a function of the electrical load. This plot is for the $5 \times 5 \mathrm{~mm}^{2}, 100-\mu \mathrm{m}$ thick PZT harvester bonded with $5 \mu \mathrm{m}$ of adhesive and subject to the $5 \mathrm{~Hz}$ gust.

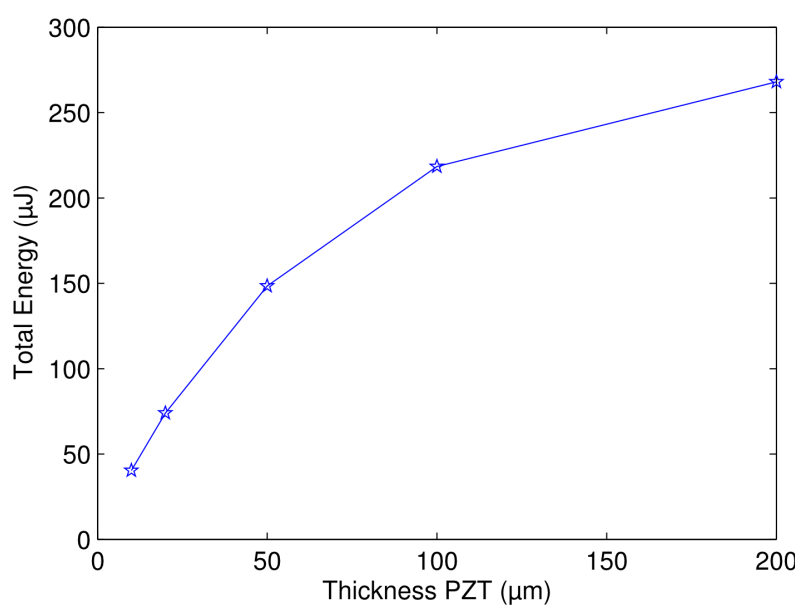

Figure 5. Total energy produced by the EH as a function of PZT thickness. The size of the PZT is $5 \times 5 \mathrm{~mm}^{2}$ and the thickness of the adhesive is $5 \mu \mathrm{m}$. Data are calculated at their own optimal value of electrical load.

The thickness of PZT influences the energy produced as shown in Figure 5: thicker PZT films yield higher energy. This is justified by the fact that, once the strain level is fixed, thicker PZT exhibit higher voltages across their electrodes, as the strain level initially defines the electric field within the material. Interestingly, however, the growth in energy is not linear, suggesting that thinner layers are, on a unit volume, more efficient than thicker ones. The reason for this is that thicker PZT layers are stiffer and the stress available is limited by the shear stiffness of the adhesive, representing the interface between PZT and substrate.

To clarify the effect of the size of PZT, the area energy density is plotted (Figure 6): the energy density increases with PZT size, suggesting that larger films of PZT are more efficient on a surface area basis. This observation is linked to the edge effect discussed later. As regards the energy values, a few joule are produced by each square meter of PZT, which translate in a power generation in the order of one $\mathrm{mW} / \mathrm{cm}^{2}$ in the first seconds after the gust event. 
The epoxy adhesive has the role of transferring the strain of the wing skin into the PZT film. For this to be efficient, the epoxy layer must be as stiff as possible. It is therefore not surprising to see that the energy produced decreases as the epoxy thickness increases (Figure 7); the effect is more pronounced with thicker PZT films, as seen by comparing the slope of the two lines in the graph.

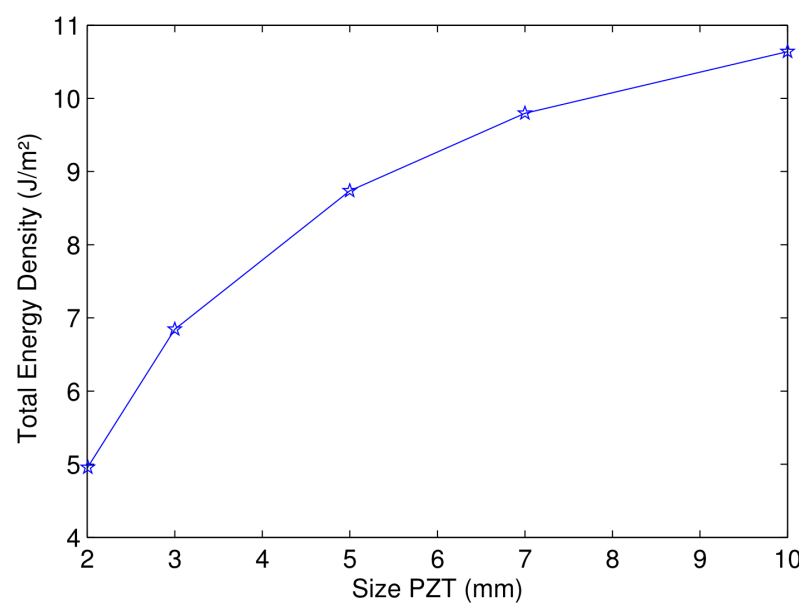

Figure 6. Total energy density produced by the EH as a function of the side length of the PZT. The thickness of the PZT and of the adhesive are $100 \mu \mathrm{m}$ and $5 \mu \mathrm{m}$, respectively. Data are calculated at their own optimal value of electrical load.

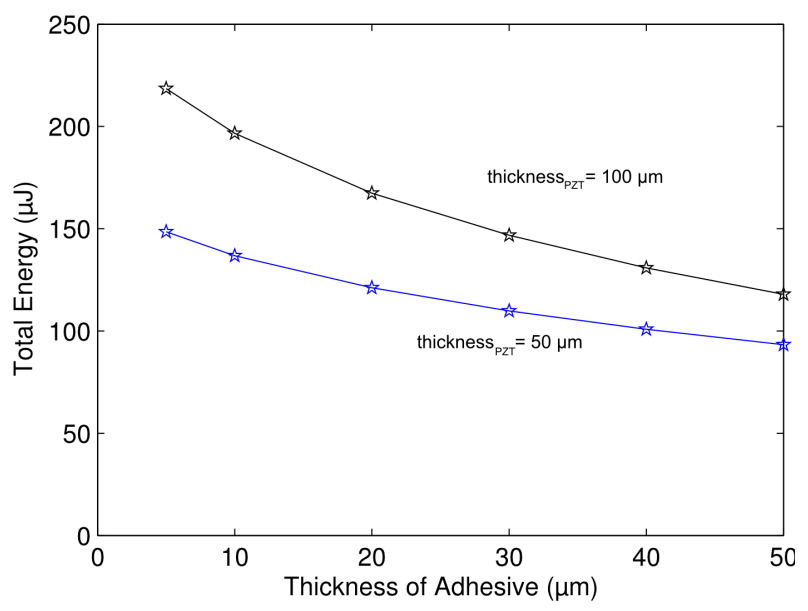

Figure 7. Total energy produced by the EH as a function of the thickness of the adhesive. Two values of thickness of PZT were considered, which are indicated in the plot; the PZT dimensions are $5 \times 5 \mathrm{~mm}^{2}$ in both cases. Data are calculated at their own optimal value of electrical load.

As regards the frequency of the gusts, significant differences are noticed among the voltage outputs of the PZT harvester under the four gust loadings (Figure 8). Their effects on the total energy produced are summarized in Table 5. A maximum is noticed for a $5 \mathrm{~Hz}$ gust, as this is close to the resonance frequency of the optimised wing $(5.4 \mathrm{~Hz})$ : the fundamental vibration mode is excited, with associated maximum strain levels (Figure 2) and subsequent ample oscillations at resonance. The energy generation for slow gusts $(1$ and $2 \mathrm{~Hz})$ is much smaller, as the strain rate (i.e. speed of deformation) of PZT is very important in defining how much electrical energy can be produced and also the 
oscillations that follow the event are rather small.

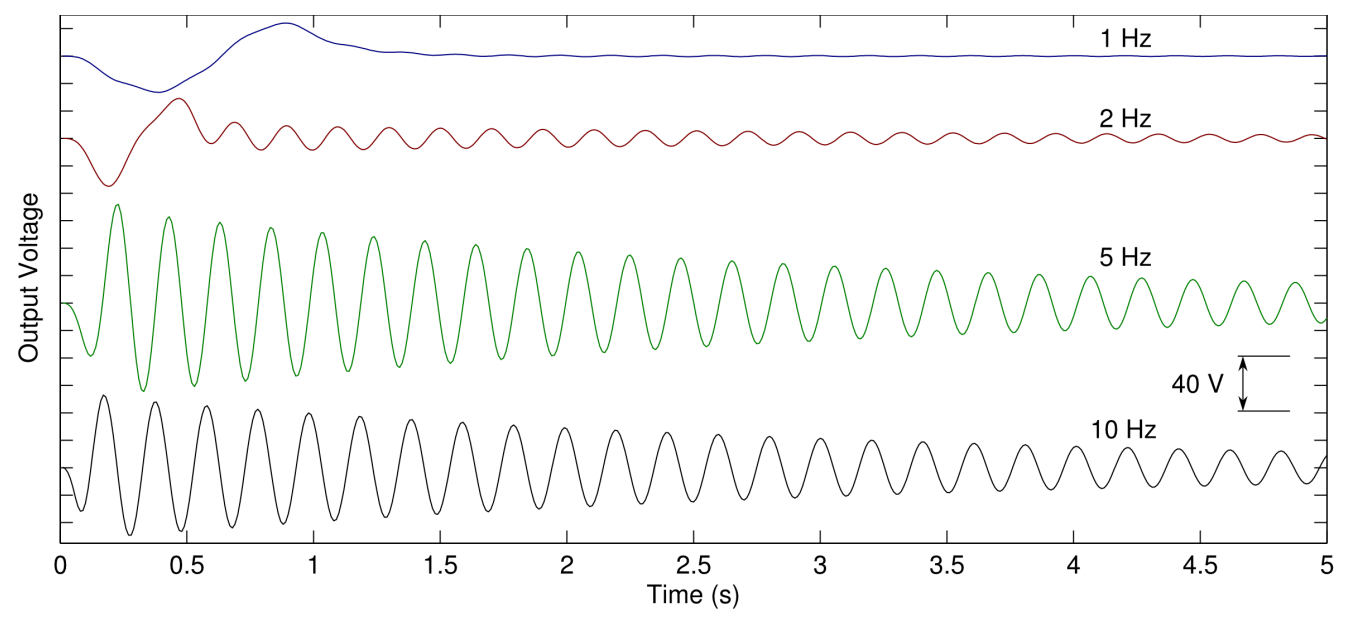

Figure 8. Comparison of the voltage waveforms produced by the $5 \times 5 \mathrm{~mm}^{2}, 100-\mu \mathrm{m}$ thick PZT harvester under the four gust loadings investigated. Each curve is obtained with its optimal electrical load (150, 80, 30 and $25 \mathrm{M} \Omega$ for frequencies from 1 to $10 \mathrm{~Hz}$, in order).

Table 5. Total energy produced by the harvester at different gust frequencies.

\begin{tabular}{cc} 
Gust Frequency & Total Energy $(\boldsymbol{\mu J})$ \\
\hline $1 \mathrm{~Hz}$ & 8.0 \\
\hline $2 \mathrm{~Hz}$ & 12.0 \\
\hline $5 \mathrm{~Hz}$ & 218 \\
\hline $10 \mathrm{~Hz}$ & 161 \\
\hline
\end{tabular}

\subsection{ENERGY HARVESTING: MODELLING DISCUSSION}

As described before, the area energy density is not constant but increases with the PZT dimensions; also, the total energy increases with the thickness of the PZT, but not as fast as a linear dependency would predict; finally, thicker layers of adhesive cause a reduced energy generation. All these phenomena can be explained by the efficiency with which the mechanical strain in the composite substrate is transferred to the PZT layer. As the PZT becomes thicker, larger forces are needed to fully strain it; as the coupling between substrate and PZT is provided by the adhesive, its finite (as opposed to infinite) stiffness sets some limits. The increase of area energy density in larger PZT films is explained by Figure 9: there is an edge effect whereby the top and bottom regions of the PZT are not subject to the full strain experienced by the rest of the material. The size of the regions affected by lower strain levels is determined by the thickness of the PZT rather than its size, so that in a larger harvester they are proportionally smaller and cause a smaller loss of efficiency.

The output impedance of the harvesters modelled is rather high, in excess of $25 \mathrm{M} \Omega$ for the $5 \times 5 \mathrm{~mm}^{2} 100 \mu \mathrm{m}$-thick 
device. Whilst these values are impractical, as the power management unit should have a matching input impedance, they are due to the small dimensions that could practically be modelled. A realistic harvester placed on an aircraft wing would be at least $100 \times 100 \mathrm{~mm}^{2}$, reducing the optimal electrical load to only tens of $\mathrm{k} \Omega$. It is worthwhile highlighting that reduced transducer thickness would bring benefit not only for the improved coupling discussed above, but also in increasing the capacitance and therefore reducing the output impedance.

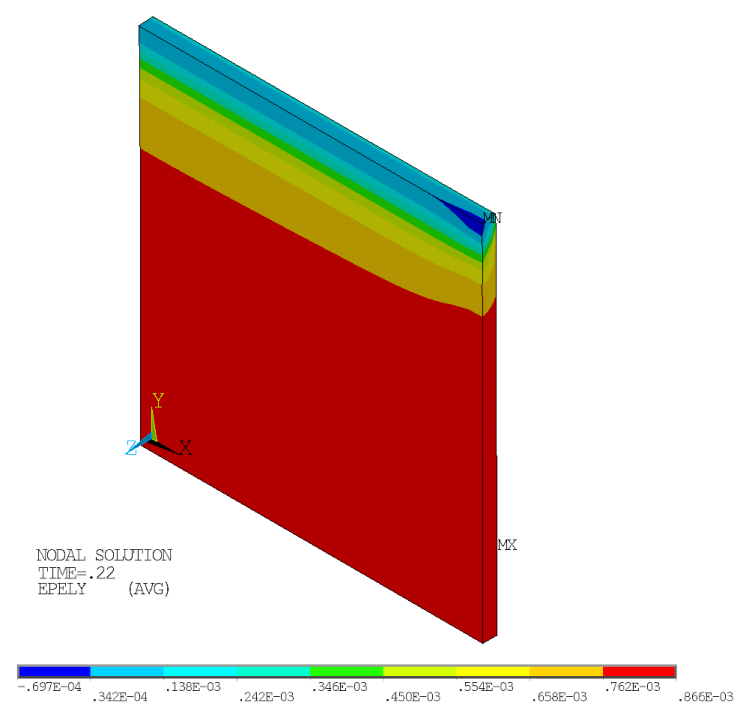

Figure 9. Modelling results of the longitudinal elastic strain (Y direction) within the PZT element. Only the quarter model is shown, the full device would be mirrored in the XZ and the YZ planes. The front side is exposed, the back is bonded with $5 \mu \mathrm{m}$ of DP460 adhesive to the composite substrate (neither of which is shown for clarity). This plot shows the peak strain ( $\mathrm{t}=0.22 \mathrm{~s}$ ) of the $2 \mathrm{~Hz}$ gust, with a $5 \times 5 \mathrm{~mm}^{2} \mathrm{PZT}$ of thickness $100 \mu \mathrm{m}$.

\section{CONCLUSIONS}

With the overall aim of reducing aircraft weight and maintenance cost, a weight-optimized wing structure was obtained and piezo-harvesters were evaluated as energy supply for wireless sensor nodes in aircraft structural health monitoring. Time-domain strain waveforms were calculated for the wing skin when the aircraft was subjected to gust loading. Whilst gusts of higher frequencies $(5$ and $10 \mathrm{~Hz})$ induce a sustained vibration of the wing, slower gusts $(1 \mathrm{and} 2 \mathrm{~Hz})$ produce a semi-static deflection of the wing.

A parametric study was carried out, which showed that large and thin PZT harvesters are to be preferred for energy generation efficiency: in a large PZT harvester, edge effects that adversely affect energy efficiency are less important; thin harvesters are more efficiently coupled to the substrate. Similarly, thin layers of adhesive are preferred for their increased stiffness and effectiveness in mechanically coupling harvester to substrate.

In this work, the PZT harvester was subjected to a strain of up to $1300 \mu$ strain, which is within the limits tolerated by bulk PZT materials for a large number of cycles. An alternative may be represented by the use of advanced composite piezoelectric materials like Micro Fibre Composites, which are expected to withstand strains of approximately 
$2500 \mu$ strain, yielding a potential 4-fold increase in energy generation.

One advantage of this energy harvesting approach is that energy is produced also during taxiing and during long flights. The most appealing feature of this energy harvesting solution is the very low profile of the harvester (the PZT film thickness is only $100 \mu \mathrm{m}$, an MFC is a few tenths of a millimetre thick), its low invasiveness and weight.

Future works should look at the statistical incidence of gusts of different frequencies and amplitudes to estimate the average power produced during a typical flight.

\section{ACKNOWLEDGEMENTS}

Part of this work was sponsored by the Cranfield's Innovative Manufacturing Research Centre (IMRC).

\section{REFERENCES}

1. Speckmann, H., Structural Health Monitoring (SHM), April 2008, http://easa.europa.eu/certification/flightstandards/doc/imrbpb-issue-papers/IMRBPB\%20IMRBPB\%20April\%2008\%20presentation.pdf

2. Samson, D., Kluge, M., Becker, T. and Schmid, U., "Wireless Sensor Node Powered by Aircraft Specific Thermoelectric Energy Harvesting,” Sensors and Actuators A: Physical, 172(1), 240-244 (2011)

3. Churchill, D.L., Hamel, M.J., Townsend, C.P. and Arms, S.W., "Strain Energy Harvesting for Wireless Sensor Networks," in Proc. SPIE 5055, 319-327 (2003)

4. Paradiso, J.A. and Starner, T., "Energy scavenging for mobile and wireless electronics," IEEE Pervasive Computing 4, 18- 27 (2005)

5. Zhu, D., Beeby, S.P., Tudor M.J. and Harris N.R., "A credit card sized self powered smart sensor node," Sensors and Actuators A: Physical, 169(2), 317-325 (2011)

6. Pozzi M. and Zhu M., "Plucked piezoelectric bimorphs for knee-joint energy harvesting: modelling and experimental validation," Smart Mater Struct. 2(5): 055007 (2011)

7. Wang J., Callus P. and Bannister M. Experimental and numerical investigation of the tension and compression strength of un-notched and notched quasi-isotropic laminates. Composite Structures 64, 297-306 (2004)

8. Kim, J.K., Kim, H.S. and Lee D.G., "Adhesion characteristics of carbon / epoxy composites treated with low- and atmospheric pressure plasmas ," J. Adhesion Sci. Technol., 17(13), 1751- 1771 (2003) 